\title{
Historical forms of the journalistic communication style in Slovakia*
}

\author{
M. Horvath \\ Comenius University in Bratislava, \\ 2, Gondova st., Bratislava 1, 811 02, Slovakia
}

For citation: Horvath, M. (2021). Historical forms of the journalistic communication style in Slovakia. Media Linguistics, 8 (2), 122-132. https://doi.org/10.21638/spbu22.2021.202

The work is based on the presumption that the journalistic (publicistic or newly mass communication) style is an integral part of the communication universe of people in the $21^{\text {st }}$ century, and its importance has increased in direct proportion with the rise of the influence of media. In the specific conditions of Slovakia, the evolution of journalism was closely related to the issue of language emancipation of the Slovaks and the strengthening of their national awareness. In later phases, it was considered partially a hybrid style of public communication that was created by a mixing of the official (also referred to as the administrative style and the negotiation style in the past) and the scientific style as well as the belles-lettres style with the aim to not only inform, but also educate, influence or persuade dispersive, heterogeneous addressees in regard to the most current events having a broader social meaning. In the current era that is influenced by the massive use of information and communications technologies, the stylistic characteristics of texts in media significantly changes prevalently towards colloquialisation which is closely related to the deprofessionalisation of the journalistic profession and the creation of citizen journalism.

Keywords: Slovak national culture, stylistics, journalism, journalistic style, publicistic style, media communication style.

It could be said that like other processes in Slovakia, the start and evolution of journalism and from it abstracted publicistic language (communication) style was significantly delayed. This was due to the long-lasting unfavourable political and social situation that did not provide the space for the emancipation of the representatives of Slovak nationality, as well as the lack of personalised nationally oriented intelligentsia, and the absence of a generally accepted language that would satisfy variable individual and societal communicational needs. Due to those circumstances it is understandable that wider publicistic (journalistic) activities in Slovakia were long inhibited and that also applies to the stylistics as a part of the systematic study of language, specifically the text-forming activities. Thus the key to the genesis of the Slovak publicistics is the solution of the language issue which in turn refers to the formation of the Slovak national culture itself, i. e. to its initiation phase.

* This article is part of a grant founded by The Ministry of Education, Science, Research and Sport of the Slovak Republic, MŠVVŠ SR VEGA 1/0111/20 Communication Culture in a Gradually Democratised Society.

(C) St. Petersburg State University, 2021 


\section{The formation of the Slovak national culture and the first newspaper written in Slovak}

As we have stated, the start and development of journalism in Slovakia is directly related to the codification and use of a language accepted throughout the whole society and land, and the language - in our case - is in turn directly related to the formation of the Slovak culture itself. Not taking into account the fact that language - and the communicational-interpretative mechanism related to it - is the constitutional element of the category of culture in general [Dolnik 2020], Slovak national culture can be considered as philological, or more specifically philologically-revivalistic, because its qualitative and quantitative growth were always dependent on the level of language emancipation. One of those who state it explicitly is A. Matuska [Matuska 2015: 146-147] in his macroessay K slovenskému národnému charakteru (On the Slovak National Character): "(...) the language aspect applies to our, Slovak, situation of the past and we could even call it the equation of nation with language. (...) This resulted in the idea, which we still hold, that we shall win if we keep our language. We have won, but with the shortcoming that the culture we have created is to a high degree philological, revivalistic."

It is evident that the Slovak national culture is from the historical perspective still a relatively young, not yet crystallised culture, which causes many functional limitations and deficiencies. As V.Minac [Minac 1997: 75] writes in this context: "Our national memory is unbelievably young. (...) We are so young that we can physically touch our birth." When searching for the roots of the Slovak national culture with respect to the language (communicational) relations, we come to two genetic hypotheses of its formation: the idealistic hypothesis, which can be due to its interpretation denoted with the attribute archetypal, and the realistic hypothesis originating from the autonomistic activities of the members of the newly founded Slovak national collective. According to the first, idealistic hypothesis we the archetype (the original source) of the Slovak national culture can be found as early as in the moment of accepting Christianity in Cisdanubia ${ }^{1}$ and thus place the birth of the Slovak national culture in the period of the arrival of Constantine (Cyril) and Methodius to Great Moravia in 863 and their subsequent activities in the sphere of the evolution of the Slavic proto-language, proto-script and numerous translations of liturgical texts in the second half of the $9^{\text {th }}$ century including the first literary work of Great Moravia - Proglas, i. e. Foreword (Opening Song) to the holy Gospels. The initial Christianisation naturally represents a starting point or even a breakthrough sociohistorical moment not only for the Slavs, but for the whole Latin-speaking European civilization. This is supported by the fact that in 1980 both saints were declared co-patron saints of Europe. In this context, we can say that Cyrillo-Methodian tradition was also an accelerator for the anticipated (at that time non-existent) Slovak national culture despite the fact that the potential continuity was violently interrupted after this relatively short initiation phase by the arrival of nomadic Hungarian tribes. Although the Magyar (Hungarian) tribes converted to Christianity thanks to Stephen I of Hungary (907-1038), they did not further develop Old Church Slavonic (Paleoslavic) education and literature. The restart of national and cultural (reviv-

${ }^{1}$ We use the older administrative division of the Kingdom of Hungary into two Capitancies, i. e. Cisdanubia (nowadays Slovakia) and Transdanubia (the rest of the Kingdom of Hungary at that time) as well as analyses of toponyms that document the presence of the Slavs in the territory north of the Danube [Stanislav 1999]. 
alist) efforts that affected language and publicistics occurred after a very long time, at the end of the $18^{\text {th }}$ and the beginning of the $19^{\text {th }}$ century depending on the preferred Christian denomination.

According to the second, realistically-autonomistic hypothesis, the starting point in the evolution of the modern Slovak national culture can be found approximately in the mid- $19^{\text {th }}$ century when the emancipation process of the Slovaks as an autonomous and ethnically relatively homogeneous nation living in the geographical middle of Europe was completed after a thought-through set of political steps, a sophisticated language codification and literary-publicistic activities. Especially due to the activities of the members of the so called Stur generation, it was possible to overcome the cultural parameter of the restriction of history and language [cf. Horvath 2016], which facilitated the formation of a relatively free Slovak publicistics (journalism) and thus also the creation of the contemporaneous publicistic communication style.

We know from history that due to the personal involvement of L. Stur, after many troubles and bureaucratic obstacles, the first issue of Slovenskje národřje novini (Slovak National Newspaper) was finally published on 1 August 1845 . This newspaper is considered to be the first modern political newspaper in the history of Slovak journalism. Stur was able to present his own political, social and journalistic programme on its pages and at the same time the newspaper also fulfilled the formal, technical, and publishing criteria of renowned contemporaneous periodicals such as Preßburger Zeitung, Wiener Zeitung or Pesti Hírlap. It was published twice a week (every Tuesday and Friday) on four numbered pages in two columns on each page and their content constituted of editorials or rather editorial articles of a revivalistic and edifying nature, current domestic and international news, as well as miscellaneous "minute" information about economy, society and culture. The literary supplement of Slovak National Newspaper was the bi-weekly Orol tatránski (The Tatra Eagle) that offered sturovci (the followers of Stur) as well as other representatives of the contemporaneous Slovak intelligentsia a broader platform for publication not only of their literary texts but also various edifying and informative materials [cf. Serafinova, Vatral 2005]. To demonstrate the visual of the newspapers we enclose the title pages of the first issue of Slovak National Newspaper [Digitálna knižnica a digitálny archív] from 1845 as well as the title page of its literary-cultural supplement (Figure $a, b$ ).

Slovenskje národñje novini (Slovak National Newspaper) was written in the so called Stur's Slovak, i. e. in the codified literary language before the key orthography reform from today's point of view - occurred and thus the excerpted texts contain certain conspicuous phonetic, morphological, and orthographic features that do not correspond with the contemporary state of the literary language [Horvath 2015: 77-78]. Although their detailed linguostylistic analysis is not the aim of this study, it is worth mentioning, that L. Stur himself selected individual journalistic articles with the utmost attention (the main reason for this was that the newspaper was under constant censorship supervision of the government due to ideological reasons) and he also paid close attention to the general intelligibility of published texts to ensure that all articles would be understandable even for less educated readers from rural parts or smaller towns [Serafinova 2015] and could impact a wider circle of potential readers. This was very important in the context of this first periodical published in Slovak, because it fulfilled not only its informative function (news), but also educative (edifying) function, opinion-forming function, in part also entertaining function, and nation-representing function. This nationally identifying or even 


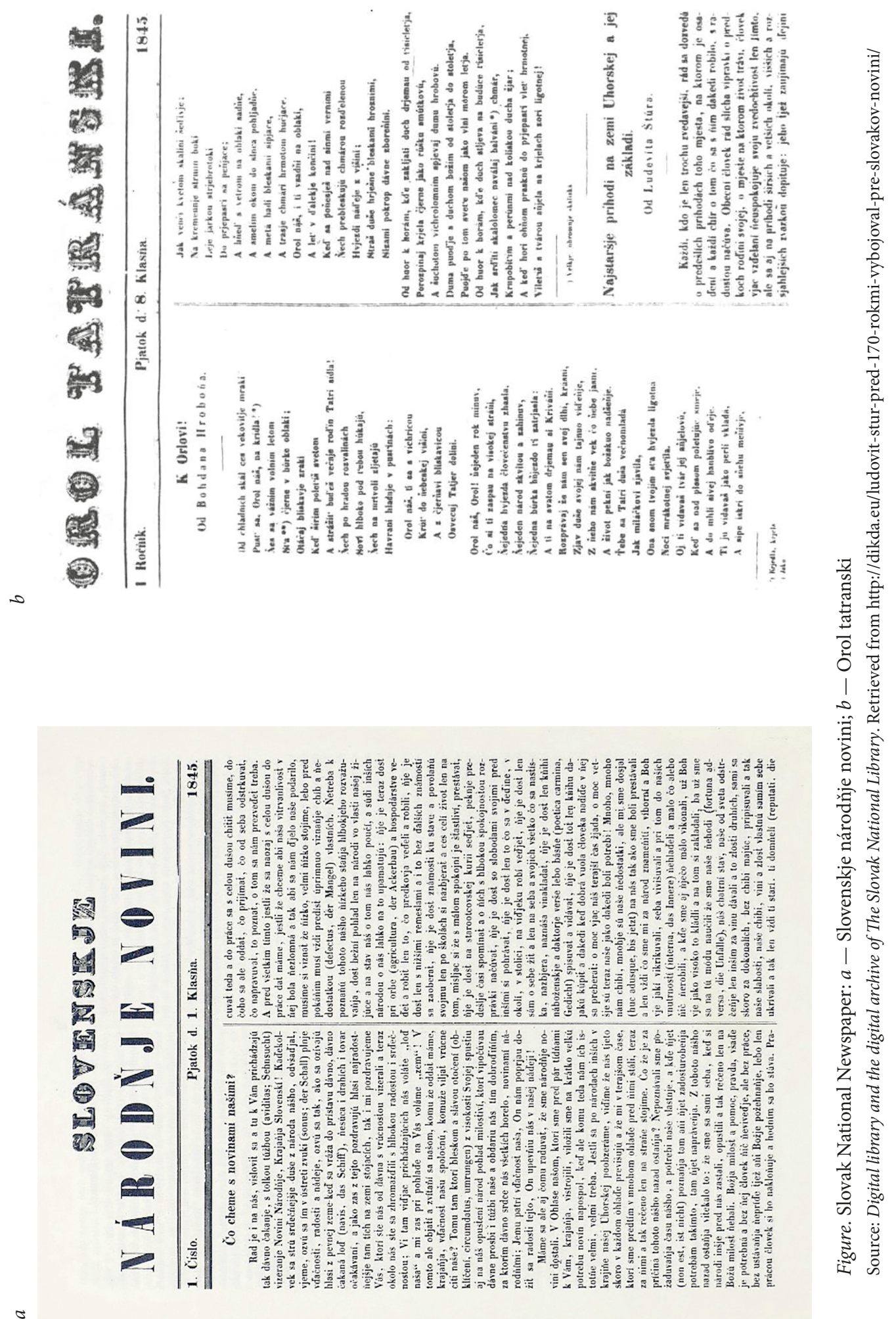


nationally revivalistic potential, residing in the strengthening of the national awareness, was a typical structurally-functional sign of the first phase of creating the publicistic (journalistic) style in Slovakia. Now it might seem redundant but it represented a significant asset for the rising Slovak national culture in the second half of the $19^{\text {th }}$ century - and thus it also influenced it later development.

\section{Structuralistic approaches to the publicistic (journalistic) ${ }^{2}$ communication style in Slovakia}

The development of practical journalism in Slovakia was stunted for a long time as well as a systematic research of journalistic texts as a part of the then forming mass media science or other communication sciences where linguistics has always played a key role. This is the reason why the publicistic (journalistic) style was not given adequate attention despite the fact that informative texts with persuasive function aimed at the reader belong to the research field of stylistics and offer sufficient research stimuli.

In the modest history of Slovak linguistic stylistics, the first attempt at profiling and practical explaining of the process of creating texts was a quite short publication by Ludovít Sensel (1888-1956), Lutheran pastor, editor and journalist who in the year 1921 published a didactic handbook titled Slovak Stylistics (Slovenská štylistika). As it was a stylistics textbook, more specifically rhetoric for high schools, Sensel's understanding of the language style and stylistics is simplified and has a markedly mentoring nature. His commentaries mostly consist of advice and guidance and do not give an exact linguistic description of stylistic terms and relations on the axis user - language - communication situation text - style. In the spirit of the rhetoric ideals of antiquity and Enlightenment he advises for example to compose texts transparently, clearly, logically as well as - in accordance with the contemporaneously preferred language purism - encourages students to use lovely, pleasingly sounding, lively and unadulterated means of expression. He divides stylistics into three parts: spoken, logical, and aesthetic; and in general, he considers stylistics in general to be the science dealing with writing which establishes the method, the law, for expressing our thoughts either in written or oral form [cf. Sensel 1921]. Sensel does not further delve into the individual communication styles and their corresponding textual structures and he does not identify or analyse relevant stylistic markers - therefore there is no explicit characterisation of the publicistic style in his work. On the one hand, the content and internal structure of Sensel's writing still belongs into the rhetoric scheme of stylistics of the period before Charles Bally, but on the other, we are convinced that even thus conceived the textbook contributed to the stabilisation of the Slovak language in the educational practice as well as in other areas of official communication (especially the official and scientific style) where after the founding of the First Czechoslovak Republic the young and still developing literary Slovak was not widely used.

The next step to analysing the complex issue of text and style in Slovakia was the publication of the university textbook The System of Literary Slovak I and II (Systém slovenského spisovného jazyka I a II) by Eugen Pauliny in 1946 and 1948 into which the author intentionally included a concise chapter about style or rather the stylistic differentiation of

${ }^{2}$ In this study, the terms publicistics and journalism are used as synonyms, even though there is a noticeable discrepancy between these terms in Slovak context. We are pointing this out in the last chapter of this paper. 
the Slovak vocabulary. Pauliny's regard of the language system was already influenced by the structuralism and functionalism of the Prague School [Vachek 1970]. According to the ideas of this school of linguistics the potential author (expedient), among other things, approaches the composition of their communication always with regard to its function and to the individual parameters of a communication situation, which after all applies even now in the second wave of the pragmatisation of stylistics [Bohunicka 2020].

In his partial conception of stylistics, Pauliny naturally followed the older works of Czech structuralists, especially B. Havranek [Havranek 1932; Havranek 1940] and J. V. Becka [Becka 1938; Becka 1948]. In accordance with the ideas of the Prague Linguistic Circle, he emphasized the role of standard (codified) language and linguistic culture in the formation of various functional language styles, while "the stratification of the national language into individual existential forms (varieties) should be the main criterion on the basis of which we assess individual stylistic works whether scientific, artistic or practical" [Becka 1948: 25], among which are also specifically functionally oriented journalistic texts. Unlike in Sensel's concept of the rhetorical stylistics and also Becka's older views on the types of styles (individual types of style, character types of style, period types styles) [Becka 1948: 389-396], in Pauliny's work we find an explicit mention of the publicistic style (along with the scientific ${ }^{3}$, the negotiation ${ }^{4}$, conversational ${ }^{5}$, literary and the style of rhetorical texts) that the author describes as a style of public communication and according to him, its production is aimed at "informing as well as persuading (and in connection with persuading also educating) a broad spectrum of readers of various ages and education; and in regard of this goal the composition and selection of linguistic devices, as well as vocabulary, used in journalistic production is adjusted in a certain way" [Pauliny 1981: 42]. On the other hand, even here we can see certain problems with characterising the publicistic style because newspapers can publish texts that are not journalistic in nature or not primarily intended for newspapers. That brings us to the issue of the internal inconsistency of the textual representations of the journalistic style as well as its perceived hybridity stemming from the crossing or syncretisation of the structural signs of the official, scientific and partially also the literary functional style. This inconsistency consequently shows on the plane of genres where an obvious fracturing of forms and genres occurs depending on the preferred way of displaying facts as well as the presence of the subject, that is the power of the personality of the journalist, editor, commentator, reporter, moderator or a different kind of journalist.

In the outline of the Slovak stylistics of the $20^{\text {th }}$ century we can see that the scientific works of E. Pauliny opened the stylistics to structuralism. In result, the functional structuralistic approach to the interpretation of the individual stylistic categories as well as the general process of creating style in both key stylistic concepts that were established in Slovak stylistics of the second half of the $20^{\text {th }}$ century - in the expressional stylistics (expressional theory of style) of F. Miko (1920-2010) and selective stylistics of J. Mistrik (19212000). Although both concepts of stylistics are based on the structuralistic foundation postulated by the Prague School of Linguistics, the difference is significant. While Miko derives the specific form of the style from the prevalent language functions in the text

${ }^{3}$ When discussing the scientific style, E. Pauliny dentifies a further unspecified theoretical style.

${ }^{4}$ The negotiation style, according to E. Pauliny, is the style of administrative and byrocratic texts.

${ }^{5}$ Pauliny's term conversational style is compatible with the present colloquial style, more specifically with the colloquiality in its broader sense. 
(here Miko applies the original organon model formulated by K. Bühler [Bühler 1965]), Mistrik sees the manifestation of a specific language style in the background of acting objective and subjective stylistic factors [Mistrik 1997; Horvath 2016], which, naturally, influences the classification of language (communication) styles on the horizontal axis.

In F. Miko's works the language (communication) style already represents a relatively complex dimension whose formation and realisation actualise various smaller (elementary) stylistic values that he calls expressional qualities or expressional categories. Style is then a dynamic configuration of these expressional qualities in a text. The primary qualities, the highest standing qualities in the hierarchy, are operativeness, iconicity, conceptuality and experienceness [Miko 1960; Miko 1970]. Iconicity of expression standing in opposition to operativeness is understood as the orientation of the text towards the depiction (image) of a certain part of the extra-linguistic reality. Operativeness, on the other hand, means the orientation of the text towards the recipient and the consequent and already guided proceedings of the recipient. In the second opposition of conceptuality and experienceness, conceptuality presumes a rational, objective depiction of reality, while experienceness presumes its emotional, subjective depiction. Due to the combination of these four categories configured into two binary oppositions, we can abstract individual primary language styles according to the following matrix: operativeness with experienceness create the colloquial style, operativeness with conceptuality create the official style, iconicity with experienceness create the belle-lettres (literary) style, and finally iconicity with conceptuality create the scientific style. As one can see no combination of the four categories unequivocally forms the journalistic style which proves its hybridity as well as a certain level of heterogeneity. Since the point of Miko's system of expressional qualities is openness and hierarchisation of the whole system, we can depict the publicistic style on lower levels of the offered expressional qualities and their derivations and thus find its position among other language (communication) styles and sub-styles.

The publicistic style as a secondary, derived style is, on the one hand, characterised by operativeness which verges into appellativeness and even persuasiveness, as well as conceptuality that merges with factuality and even reticence. On the other hand, this style also seems to contain iconicity that on lower levels of the expressional system manifests in its factuality, in details and even enumeration, while in the more literary journalistic genres we can contemplate the actualisation of experienceness which presumes subjectivity and emotionally expressive depiction of reality. It is evident that the journalistic language style is in regard to the presented system of expressional qualities significantly ambivalent (it is characterised by operativeness and thus it verges towards the official style, but it is also characterised by iconicity which brings it closer to the scientific style), while in connection with the perpetually increasing influence of the media in the current post-modern discourse, operativeness and from it derived persuasiveness often transits into bias or manipulation of the anonymous addressee.

The second mentioned linguist, J.Mistrik, developed his concept of style and stylistics (based on the acting objective and subjective stylistic factors) gradually since the publishing of Praktickej slovenskej štylistiky (Practical Slovak Stylistics) in 1961 up to the third revised edition of his compendium Stylistika (Stylistics) in 1997. Although J. Mistrik unlike F. Miko includes the publicistic (journalistic) style together with colloquial, bellelettres, scientific, administrative and rhetorical among the primary functional styles and characterises it as a relatively independent subjectively-objective style whose goal is to 
bring swift, accurate and persuasive information about current issues concerning wider public [Mistrik 1997], but at the same time he relativizes its place among the primary style when he claims that in one of its elements it is "an organic continuation of the rhetorical style" [Mistrik 1997: 459], its other elements, according to him, are closer to the official or literary style, not taking into account the terminological saturation characteristic for the scientific style. According to J.Mistrik [Mistrik 1997: 468] the internal heterogeny in the texts of the journalistic style is the most evident on the level of genres where they divide, based on their functional stylistic intention, into news, analytical, and belletristic. The approximation towards the genres of the official style is apparent in news genres, the analytical genres lean towards the rhetorical style, and in the belletristic genres we see a conspicuous actualisation of structural features that originally belonged to the literary style.

The stated trichotomy established in the functionally oriented stylistics in Slovakia is reflected in the classification of genres which is currently used in Slovak theory of journalism and mass communication. In the relation to this classification, Slovak journalism is divided into news (informative genres) and publicistics, which is in this case a subordinate (or rather a narrower term than journalistics). News represents a solely matter-of-fact, informative and maximally objectivised approaches to depicting the socially relevant events, while publicistics also presumes an element of explicit or implicit subjective evaluation, which implies a higher variability of used linguistic devices. On a lower level of abstraction publicistics is divided into two subtypes - the publicistics of the rational type and the publicistics of the emotional type [Velas 2000; Tuser, Follrichova 2001; Follrichova 2012; Roncakova 2019]. The overview genres or rather of specific textual realisations represented in the aforementioned subcategories of journalism proves that they correspond with Mistrik's division into news genres, analytical genres (publicistics of the rational type) and belletristic genres (publicistics of the emotional type).

We can state that with regard to current practices of mass media and the momentary media production the mentioned classifications of genres established in linguostylistics as well as in journalistics seem to be obsolete. Classical news genres, e. g. short report, expanded report, commented report, press note, notice, interview, message etc. are nowadays significantly ideologised and to a certain level subjectivised, moreover, their function is partially substituted by quickly rising citizen journalism; analytical genres such as editorial, commentary, column, review etc. are cultivated only under specific media conditions and as a rule they attract only experienced journalists or, and that is more common, professionals from other fields; belletristic genres such as feuilleton, causerie and others are retreating quickly and they are published more often in electronic media than in static (print) media. These and other, here not mentioned, eventualities lead us to the conclusion that to depict the modern media trends we need to use different criteria than the ones applied in classical functional stylistics, i. e. mass media science until the $90 \mathrm{~s}$ of the $20^{\text {th }}$ century. For example one feasible option would be a differentiation of media production according to the medium: print, radio, television, digital interactive media test etc. Written journalistic production would be then divided into broadsheet, tabloid, and lifestyle, traditional or in general into so called hardform and softform journalism [Roncakova 2016]. Specific attention needs to be paid to the phenomenon of citizen journalism as well as to the very popular social media, which represent such a strong competition for the old and the new media that in certain matters they have started to substitute them. 


\section{Post-structuralistic approaches to mass media texts and the new media reality}

From the point of view of the contemporary trends related to the postmodernist projection of culture, it is evident that classical, functionally structuralist approaches to the differentiation and subsequent characterisation of journalistic (publicistic) texts that were applied in Slovakia for more than half a century only marginally correspond to the current media reality. After the Velvet Revolution in 1989, which closed one chapter in the history of Czechoslovakia, the development of media in Slovakia has begun to copy the situation existing in Western democracies with all the positives and negatives that stem from it. This means, among other things, the growing influence of media on society and the life of the individual, as well as an increasingly more difficult orientation in the flood of information of different kinds and of different level of truthfulness.

As a result of the pragmatic shift in communication, Slovak linguostylistics has inevitably been pragmatised since the early 1990s, which is evident in relation to the media communication style, mainly in the fact that researchers are increasingly focusing on describing and interpreting interactive spoken (oral) media communications based on the exchange of communication roles. Although J. Mistrik in his Stylistics from 1997 already set aside a separate space for the issue of television and radio journalism, the systematic processing and in-depth analysis of public spoken communication did not take place in Slovakia until the end of the last century [Patras 2003]. At the present time marked by a massive digitisation and digitalisation, falling within the scope of the so-called fourth industrial revolution [Orgonova, Kazharnovich 2020], we talk in relation to stylistics about the so-called second wave of pragmatisation, which manifests itself in the methodology of stylistics not only by the fact that the stylistic interpretation gradually shifts its emphasis from the expedient to the percipient or to the mutual interaction (the ensuring of the optimal "strategy" in communication) of all actors involved in communication, but especially by identifying with the fact that prioritizing the procedural component of communication precludes instrumental treatment of language as an inventory of ready-made means of communication [Orgonova, Bohunicka 2018: 30-36]. As a result of such stylistic research, especially of dialogical communication, as well as the general observation of media reality in Slovakia in the first two decades of the $21^{\text {st }}$ century, we can conclude that the whole mass media communication sphere is increasingly commercialised, thus blurring the distinction between serious (opinion-forming) and tabloid (sensationalist) media ${ }^{6}$, and the influence of corporate media organisations (media giants) as well as electronic (digital) media is getting stronger at the expense of nowadays obsolete, classical audiovisual media such as radio or television which leaves space for the creation of hybrid, more precisely conversion models of media communication, e. g. very popular podcasts [for the latest on this issue Piatkova 2019], not to mention that the need for institutional media education is currently becoming more urgent [Hacek 2013] — this would streamline the process of selecting the offered information and prevent possible media manipulation. These, as well as other tendencies and phenomena, are naturally reflected in the language of media,

${ }^{6}$ The stated opposition of opinion-forming or serious media vs. tabloid (sensationalist) media, which was used in journalistic theory as well as practice until mid 90 s of the $20^{\text {th }}$ century, has been replaced by the opposition of mainstream media vs. alternative media. 
which is becoming significantly colloquiallised and trivialised, and thus increases its potential interaction.

\section{Conclusion}

At the end of our excursion into the history of the publicistic (journalistic) style in Slovakia, we would like to draw attention to another eventuality. In the Slovak media discourse, there has long been a striking terminological discrepancy between the terms publicistics and journalism. These are sometimes considered synonymous, which is reflected in their common interchangeability, other times one of the terms is considered superior over the other and vice versa. Discrepancies occur especially when we confront the conceptual nomenclature of linguostylistics and mass media science. While in the Slovak theory of journalism and mass communication, as we have stated above, the term journalism is superior to the term publicistics, as it includes three existential forms of journalism, namely news, publicistics of the rational type, and publicistics of the emotional type, in linguostylistics, as well as in the imagination of most lay people, it is exactly the opposite, as people can publish information and with it misinformation and hoaxes, but also opinions or even photographs, audio or audiovisual recordings without being professional journalists, and thus do not have to apply in communication specific, functionally burdened means of expression [cf. Barnova 2014]. This idea is supported by the practice of so called new media including social media which offer publishing space to a virtually infinite number of computer-literate people. Non-professionals then can publish their commentaries and opinions on anything, which creates "a mounting public pressure on journalistic professionals to search for such created works, accept them as relevant information sources, and in case they miss such a source, the public considers it a failure of their professionalism" [Samelova 2018: 27]. Journalists become only some kind of observers of the media space, regardless of whether they work in the newsroom or publicistics, and on the other hand, ordinary people acquire the status of modern reporters, correspondents or commentators, regardless of their professional or linguistic competencies.

Given that the mentioned terminological inconsistency concerns both linguostylistics and mass media science, it should be in the interest of both scientific disciplines to eliminate it as soon as possible and thus legitimize the relationship between journalism and publicistics. In the pragmatically oriented compendial stylistics of the Slovak language, which is currently being prepared by a team of researchers from the Department of Slovak Language, Faculty of Arts, Comenius University in Bratislava, the original term publicistic language (functional) style is replaced by the term media communication style, which we have already used in this study.

\section{References}

Barnova, K. (2014). Journalism - publicistics - politics - media: touches and intersections. Motus in verbo, $3(1), 17-23$.

Becka, J. V. (1938). Style technique. Handbook of practical stylistics. Praha: Bursik a Kohout.

Becka, J. V. (1948). Introduction to Czech stylistics. Prague: R. Mikuta.

Bohunicka, A. (2020). Pragmatization of stylistics. Journal of linguistics, 71 (2), 281-291.

Bühler, K. (1965). Language Theory: The Representative Function of Language. Stuttgart: G. Fischer.

Dolnik, J. (2020). Communication culture. Slovak Language, 85 (1), 8-27.

Follrichova, M. (2012). Emotional Type of Journalism. Bratislava: Comenius University. 
Hacek, J. (2013). Media training - Education from the cradle to the grave. Questions of Journalism, $56(1-2), 128-138$.

Havranek, B. (1932). Tasks of standard language and its culture. In B. Havranek, M. Weingart (Eds), Standard Czech and language culture (pp. 32-48). Prague: Melantrich.

Havranek, B. (1940). Stylistics (keyword). In Otto's Educational Dictionary of the New Era. Additions to the Great Otto's Educational Dictionary. Vol. 1 of 6 (pp. 471-473). Prague: Novina.

Horvath, M. (2015). Language-codification and cultural activities of Ludovit Stur. Questions of Journalism, $58(3-4), 73-80$.

Horvath, M. (2016a). Parametrization of Slovak national culture on the axis of domestic versus foreign. Studia Academica Slovaca, 45, 114-128.

Horvath, M. (2016b). Stylistics of Contemporary Slovak Language. Bratislava: Comenius University.

Matuska, A. (2015). To the Slovak national character. In A.Matuska, About Ideational Collaboration (pp. 133-154). Bratislava: Marencin PT.

Miko, F. (1960). Style. Bratislava: Slovak Pedagogical Publishing House.

Miko, F. (1970). Text and Style. Bratislava: Smena.

Minac, V. (1997). This is Where the Nation Lives. In V.Minac, Selected Disputes (pp. 75-98). Bratislava: National Literary Center.

Mistrik, J. (1961). Practical Stylistics of Slovak Language. Bratislava: Slovak Pedagogical Publishing House.

Mistrik, J. (1997). Stylistics. Bratislava: Slovak Pedagogical Publishing House.

Orgonova, O., Bohunicka, A. (2018). Interaction Stylistics. Bratislava: Comenius University.

Orgonova, O., Kazharnovich, M. (2020). New challenges to the stylistics of media communication in the digital era: The topic of Coronavirus in the public interactions of Slovaks. Studia Academica Slovaca, 49, 177-196.

Patras, V. (2003). Political communication in Slovak media conditions. In S. Cmejrkova, J.Hoffmanova (Eds), Language, Media, Politics (pp. 174-216). Prague: Academia.

Pauliny, E. (1981). Grammar of Slovak Language. Bratislava: Slovak Pedagogical Publishing House.

Piatková, K. (2019). Podcasts in contemporary Slovak journalism. Slovencinar, 6 (3), 16-21.

Roncakova, T. (2016). Contemporary Genres of Journalism: New and Old-new Models in Slovak Social Weekly Magazines. Ruzomberok: Verbum.

Roncakova, T. (2019). Genres of Journalism. Ruzomberok: Verbum.

Samelova, A. (2018). The Power and Truth in Terms of the Radio and Television of Slovakia. Bratislava: Comenius University.

Serafinova, D., Vatral, J. (2005). Outline of the History of Slovak Journalism. Ruzomberok: Catholic University.

Serafinova, D. (2015). Editors, collaborators and correspondents of Slovenskje narodnje novini. Questions of Journalism, 58 (3-4), 46-53.

Stanislav, J. (1999). Slovak South in the Middle Ages I. Bratislava: National Literary Center.

Sensel, L. (1921). Slovak Stylistics. Liptovsky sv. Mikulas: Tranoscius.

Tuser, A., Follrichova, M. (2001). Theory and Practice of Journalistic Genres I. Bratislava: Comenius University. Vachek, J. (Ed.) (1970). At the base of the Prague School of Linguistics. Prague: Academia.

Velas, S. (2000). Theory and Practice of Journalistic Genres II. Bratislava: Comenius University.

Received: November 27, 2020

Accepted: January 30, 2021

Author's information:

Milos Horvath — PhD in Linguistics, Assistant Professor; milos.horvath@uniba.sk 